\title{
Credit Risk and Underlying Asset Risk*
}

\author{
JONG-RYONG LEE ${ }^{* *}$ \\ Kangwon National University \\ Gangwondo, Korea
}

\begin{abstract}
This paper develops the credit risk of simple risky bond (Merton 1974) as expected option return to the maturity and analytically presents that the credit risk is influenced by the underlying asset risks. The paper moreover shows that the direction and magnitude of the influence depends on what the underlying asset risks are. Simulation results indicate that the relations between the credit risk and the asset risks are different among asset risks.
\end{abstract}

Keywords: Credit Risk, Expected Option Return, Pricing of an Option, Pricing of Risky Bond, Relation between Credit Risk as Expected Option Return and Asset Risk

\section{INTRODUCTION}

From Black and Scholes (1973) and Merton (1973) (BSM 1973), several option pricings in continuous time are developed and applied to the different fields. The relations among the parameters are theoretically examined (e.g., Galai and Masulis (1976); Chaudhury (2017); Hu and Jacobs (2017)). As the relations, the influence of underlying forces to the parameters as well are empirically examined (e.g., Broadie, Chernov, and Johannes (2009); Coval and Shumway (2001); Goyal and Saretto (2009)). From the empirical

* The author thanks Bokhyeon Baik (the Editor) and appreciates the unknown referee's valuable comments.

** College of Business Administration, Kangwon National University, Gangwondo, 24341, Korea. E-mail: leejr@kangwon.ac.kr, Tel: 82-33-250-6158. 
examination, the evidence is considered directly as a proof on the theoretical relations and the influence. However, the theoretical relations and the influence are about the linkages among the parameters imaginary. The parameters in Merton's model (Merton 1974) widely applied in practice and in academic research (Bharath and Shumway 2008) are also invisible.

This paper rewrites the credit risk of simple risky bond (Merton 1974) with respect to expected option return. Merton builds the credit risk as the yield to maturity upon the assumption that the risky bond is continuously traded in a risk neutral market; the credit risk excludes the drift term of the underlying asset. The paper revises the credit risk with the presumption that the risky bond is held to the maturity in the risk neutral market. The credit risk revised as the expected option the maturity (e.g., Bharath and Shumway (2008); Broadie, Chernov, and Johannes (2009); Coval and Shumway (2001)) includes the term of the expected asset return. The expected asset return may be governed by the underlying asset beta and market risk in a continuous time capital asset pricing model (Merton 1980). Of the underlying asset beta and market risk, the change could cause the credit risk revised move up and down.

This article also distinguishes from the theoretical literature (e.g., Galai and Masulis (1976); Chaudhury (2017); Hu and Jacobs (2017)). They analyze the relations among the instantaneous parameters unobservable. In contrast, the credit risk as expected option return is a function of the underlying asset risks measurable. Between the credit risk and the underlying asset risks, the relations are examined with simulation. Simulation results imply that the relations differ among the underlying asset risks. As an underlying asset risk, the increase of market variance may induce the decrease (increase) of the credit risk in the case that market risk premium is increasing (decreasing) function of market variance.

The remaining in this article is organized as follows. The next section develops the credit risk of simple risky bond as the expected option return to the maturity. The following section provides simulation results of the relations between the credit risk and asset risks to validate the relations between the credit risk and asset risks. The final section concludes the article. 


\section{THE CREDIT RISK IN EXPECTED OPTION RETURN}

This section revises the credit risk of simple risky bond provided by Merton (1974) from the viewpoint of the expected option return to the maturity and analyzes the relations between the credit risk and underlying asset risks in an inter-temporal capital asset pricing model (Merton 1980). Without the loss of logic, the argument $t$ denoting time is omitted.

Keeping in the line with the mild conditions in Merton (1974, p.450), this paper assumes that the securities issued by a corporate consist only of one share of zero coupon bond with maturity date $T$, the face value $K$ and discount rate $r$ and one share of common stock and that the asset value $S$ has the dynamics as the followings.

1. The continuous rate of interest $r$ is known and constant.

2. The asset value of a firm $S$ without any loss has the dynamics of geometric Brownian motion as the following,

$$
d S=\mu S d t+\sigma S d Z
$$

where both the drift $\mu$ and the volatility $\sigma$ are constant and $Z$ is a standard Brownian.

3. The value of the risky bond at the maturity $T B_{T}$ is the following,

$$
B_{T}=\min \left(S_{T}, K\right)=S_{T}-C_{T}
$$

where $C_{T}=\max \left(S_{T}-K, 0\right)$ is the value of the common stock as European call option on $S_{T}$ at $T$.

Then, the application of the formula as given in the Appendix (Rubinstein 1984) leads the expected value for the remaining time to the maturity $T$ to the following,

$$
\mathbf{E}\left(C_{T} \mid S\right)=S e^{\mu T} N(d)-K N(d-\sigma \sqrt{T})
$$

where $\mathbf{E}\left[\cdot^{\cdot}\right]$ is a natural expectation, $N\left[^{\cdot}\right]$ is a cumulative normal density function, and

$$
d=\frac{\ln \left(\frac{S}{K}\right)+\left(\mu+\frac{1}{2} \sigma^{2}\right) T}{\sigma \sqrt{T}}
$$


Furthermore, the calculation of the expected value $\mathbf{E}\left(S_{T} \mid S\right)$ yields the expected value of the risky bond as the following,

$$
\mathbf{E}\left(B_{T} \mid S\right)=S e^{\mu T} N(-d)+K N(d-\sigma \sqrt{T})
$$

Then, the consideration of the procedure in Merton (1974) leads the credit risk as the expected return of the risky bond to the maturity $R(0, T) T$ to the following,

$$
R(0, T) T=r T-\ln \left[\frac{1}{K} \mathbf{E}\left(B_{T} \mid S\right)\right]
$$

Now, the differentiation of $R(0, T) T$ with respect to the underlying asset variance measurable over the period to the maturity $\sigma^{2} T$ yields the sensitivity of $R(0, T) T$ to $\sigma^{2} T$ as the following,

$$
\frac{\partial(R(0, T) T)}{\partial\left(\sigma^{2} T\right)}=\frac{S e^{\mu T} N^{\top}(-d)}{\mathbf{E}\left(B_{T} \mid S\right)} \frac{1}{2 \sqrt{\sigma^{2} T}} \geq 0
$$

where $N^{\prime}(\cdot)$ is a normal density function. Thus, the relation between $R(0, T) T$ and $\sigma^{2} T$ is non negative for the other things being equal.

Next, to obtain the sensitivity of $R(0, T) T$ to market risks measurable over the period to the maturity, the paper adds the assumption that the underlying asset dynamics is governed by an inter-temporal CAPM as described by Merton (1980) as the following,

$$
\mu=r+\beta\left(\mu_{m}-r\right)
$$

where $\beta$ and $\left(\mu_{m}-r\right)$ are respectively the asset beta and the market risk premium in continuous time. Then, the drift of the common stock in continuous time $\mu_{C}$ is satisfied with the following (BSM 1973),

$$
\mu_{C}=r+\beta_{C}\left(\mu_{m}-r\right)
$$

where the call option beta $\beta_{C}$ is linked to $\beta$ as the following,

$$
\beta_{C}=\frac{\partial C}{\partial S} \frac{S}{C} \beta
$$


Keeping in the line with the arguments in Merton (1980), the paper moreover assumes that both $\beta_{C}$ and $\left(\mu_{m}-r\right)$ are stable over the period the maturity and that $\left(\mu_{m}-r\right) T$ is a function of the market variance measurable $\sigma_{m}^{2} T$ as the following,

$$
\left(\mu_{m}-r\right) T=f\left(\sigma_{m}^{2} T\right)
$$

Then, the expected underlying asset return $\mu T$ is a function of $\sigma_{m}^{2} T$ as the following,

$$
\mu T=r T+\left(\frac{C}{S N(d)} \beta_{C}\right)\left[f\left(\sigma_{m}^{2} T\right)-0.5 \sigma_{m}^{2} T\right]
$$

Furthermore, the differentiation of (12) with respect to $\sigma_{m}^{2} T$ leads the sensitivity of $R(0, T) T$ to $\sigma_{m}^{2} T$ as the following,

$$
\frac{\partial(R(0, T) T)}{\partial\left(\sigma_{m}^{2} T\right)}=-\frac{S e^{\mu T} N(-d)}{\mathbf{E}\left(B_{T} \mid S\right)}\left(\frac{C}{S N(d)} \beta_{C}\right)\left[f^{\prime}\left(\sigma_{m}^{2} T\right)-0.5\right]
$$

Thus, the credit risk $R(0, T) T$ may be negatively (positively) affected by $\sigma_{m}^{2} T$ under the extent that the relation between market risk premium and market variance is indistinct as the following,

$$
\frac{\partial(R(0, T) T)}{\partial\left(\sigma_{m}^{2} T\right)} \begin{cases}<0 & \text { if } f^{\prime}\left(\sigma_{m}^{2} T\right)>0.5 \\ =0 & \text { if } f^{\prime}\left(\sigma_{m}^{2} T\right)=0.5 \\ >0 & \text { if } f^{\prime}\left(\sigma_{m}^{2} T\right)<0.5\end{cases}
$$

Moreover, even that the market risk premium is irrelevant to the market variance, the credit risk $R(0, T) T$ is affected by asset beta measurable $\beta T$ as the following,

$$
\frac{\partial(R(0, T) T)}{\partial(\beta T)}=-\frac{S e^{\mu T} N(-d)}{\mathbf{E}\left(B_{T} \mid S\right)}\left(\mu_{m}-r\right) T \leq 0
$$

Thus, the relation between $R(0, T) T$ and $\beta T$ is non positive for the other things being equal.

In a summary, the relations between the credit risk to the maturity and the underlying asset risks measurable are vague; the increase of market variance causes credit risk increase in some 
conditions and decrease in other conditions. The relations between the credit risk and asset risks are investigated through simulation by next section.

\section{SIMUATION RESULTS}

This section provides simulation results on the sensitivity analyses of credit risk derived in the previous section to asset variance, market variance, and asset beta measurable. The simulation in the section needs several inputs including the credit risk value of a risky bond issued by a firm. The firm as selected for the purpose of simulation is Samsung Electronics Co. (SEC) listed in Korea Exchange. The value of the total asset $S$ is measured with the market value of the common stocks plus the face value of total debt $K$ (Bharath and Shumway (2008)). The face value is equal to the book value of the total current liability and half the value of the total long-term liability in the last day of 2016. The annualized mean of the total asset value return, the annualized variance of the total asset value return $\sigma^{2} T$, and call option delta $N(d)$ are estimated from the procedure provided by Bharath and Shumway

Table 1. Simulation inputs. Table 1 reports simulation inputs on Samsung Electronics Co. (SEC) as the firm issuing one year bond, the short descriptions, and the initial values.

\begin{tabular}{l|l|c}
\hline \hline Input & \multicolumn{1}{|c|}{ Description } & Value \\
\hline$S$ & Total asset value & 307.0 (\# trillion) \\
\hline$K$ & Total liability value & 61.0 (\# trillion) \\
\hline$E$ & Market value of common stocks & 246.0 (\# trillion) \\
\hline$\mu T$ & Annualized mean of returns of the total asset value & $16.8(\%)$ \\
\hline$\sigma_{C}^{2} T$ & Annualized variance of returns of the common stock & $1.5(\%)$ \\
\hline$\mu_{m} T$ & Annualized mean of returns of market portfolio & $3.4(\%)$ \\
\hline$\sigma_{m}^{2} T$ & Annualized variance of returns of market portfolio & $0.1(\%)$ \\
\hline$r T$ & Annual risk free rate in the last month & $1.6(\%)$ \\
\hline$\beta_{C} T$ & Annual common stock beta & 1.36 \\
\hline$N(d)$ & Estimated call option delta & 1.00 \\
\hline$\sigma^{2} T$ & Estimated variance of returns of the total asset value & $5.5(\%)$ \\
\hline
\end{tabular}


(2008). The procedure needs the monthly data for the value of total asset and the face value of total liability, the daily ones for the market capitalization, and annual risk-free rate $r T$. The procedure also needs the annualized asset variance $\sigma_{C}^{2} T$. Furthermore, the simulation requires annual asset beta $\beta_{C} T$, the annualized mean of market portfolio $\mu_{m} T$, and annualized variance $\sigma_{m}^{2} T$ of market portfolio. All of the data including monthly KOSPI200 index returns in 2016 as proxy for market portfolio and the annualized market yield of three year Korea Treasury Bond as proxy for the risk-free rate $r T$ in 2016 for the simulation are obtained from Fn guide. Table 1 reports the simulation inputs and their short descriptions.

Figure 1 illustrates the relation between credit risk and asset variance. In figure $1, \mathrm{X}$ - and $\mathrm{Y}$-axis stand respectively for different asset variance values and its corresponding credit risk ones as

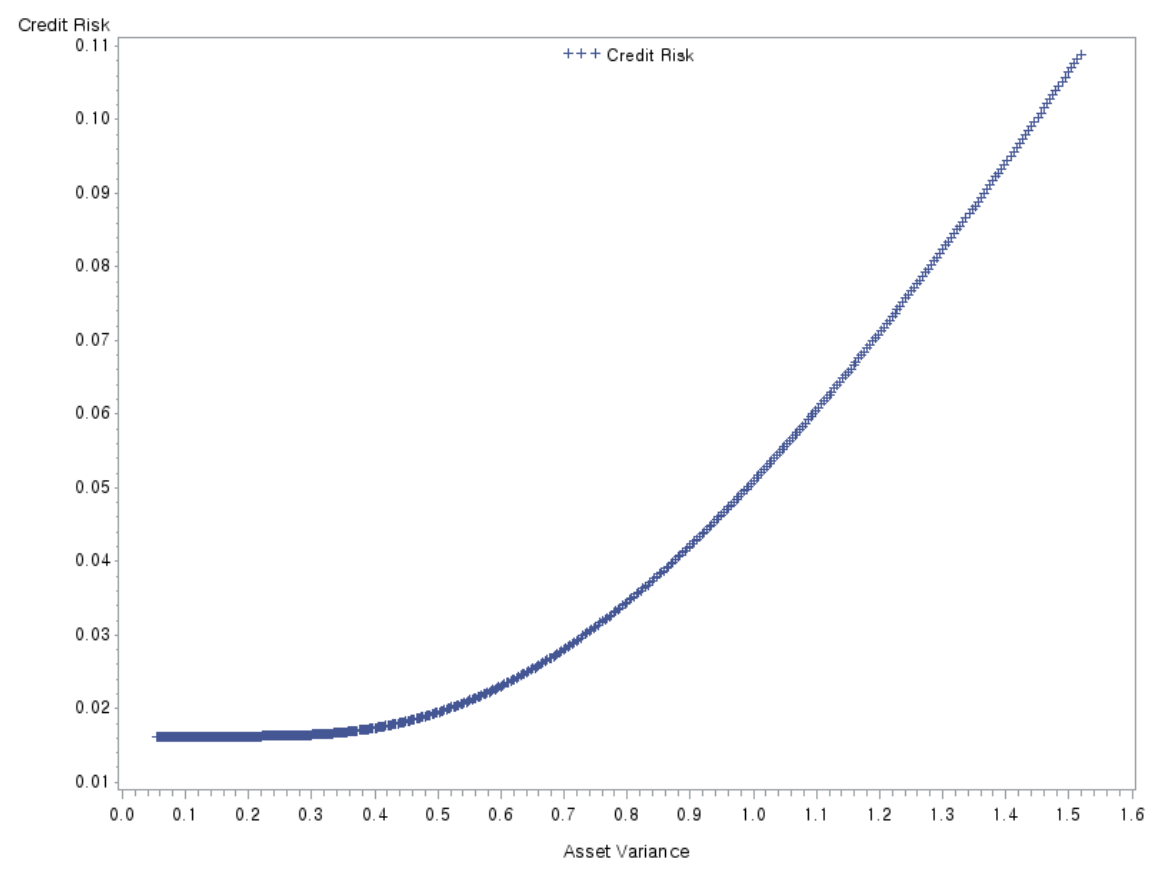

Figure 1. Credit risk and asset variance. Figure 1 depicts the relation between the credit risk to the maturity as expected option return and the asset variance. The $\mathrm{X}$-axis and $\mathrm{Y}$-axis stand respectively for asset variance values and its corresponding credit risk values obtained from the simulation. Blue crosses are for the relation between the credit risk and asset variance value. 


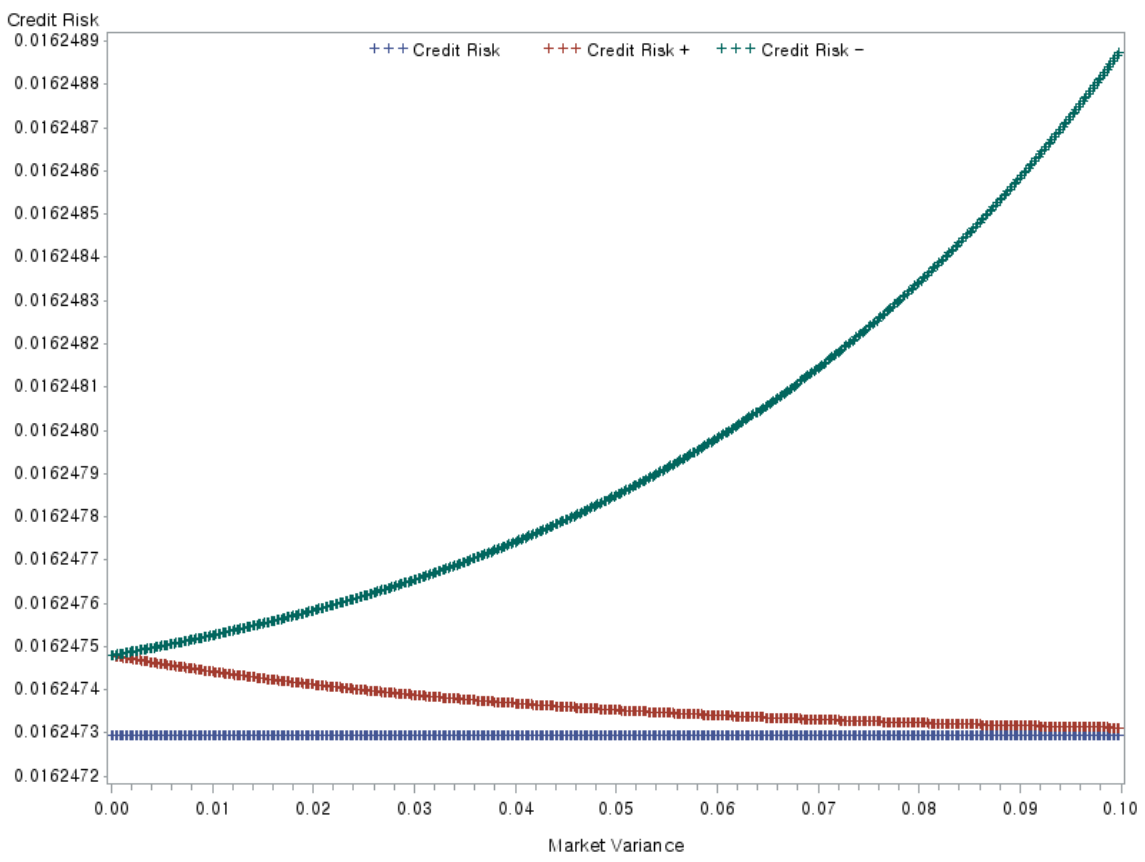

Figure 2. Credit risk and market variance. Figure 2 reports the relations between the credit risk to the maturity as expected option return and the market variance. In the Figure 2, the $\mathrm{X}$-axis and $\mathrm{Y}$-axis stand respectively for market variance values and its corresponding credit risk values obtained from the simulation. Green, red, and blue crosses are respectively for the relations between the credit risk and the market variance when the sensitivity of market risk premium to market variance is equal to $-1,1$, and 0 .

calculated with the simulation inputs for the other inputs being equal. As shown, credit risk exponentially increases as asset variance does.

Figure 2 presents the relation between credit risk and market variance. In the Figure 2, $\mathrm{X}$ - and $\mathrm{Y}$-axis stand respectively for different market variance values and its corresponding credit risk values for the other inputs being equal. Green, red, and blue crosses represent respectively the relations between the credit risk and the market variance when the sensitivity of market risk premium to market variance $f^{\prime}\left(\sigma_{m}^{2} T\right)$ is equal to $-1,1$, and 0 . As the Figure 2 shows, the relation between credit risk and market variance is 


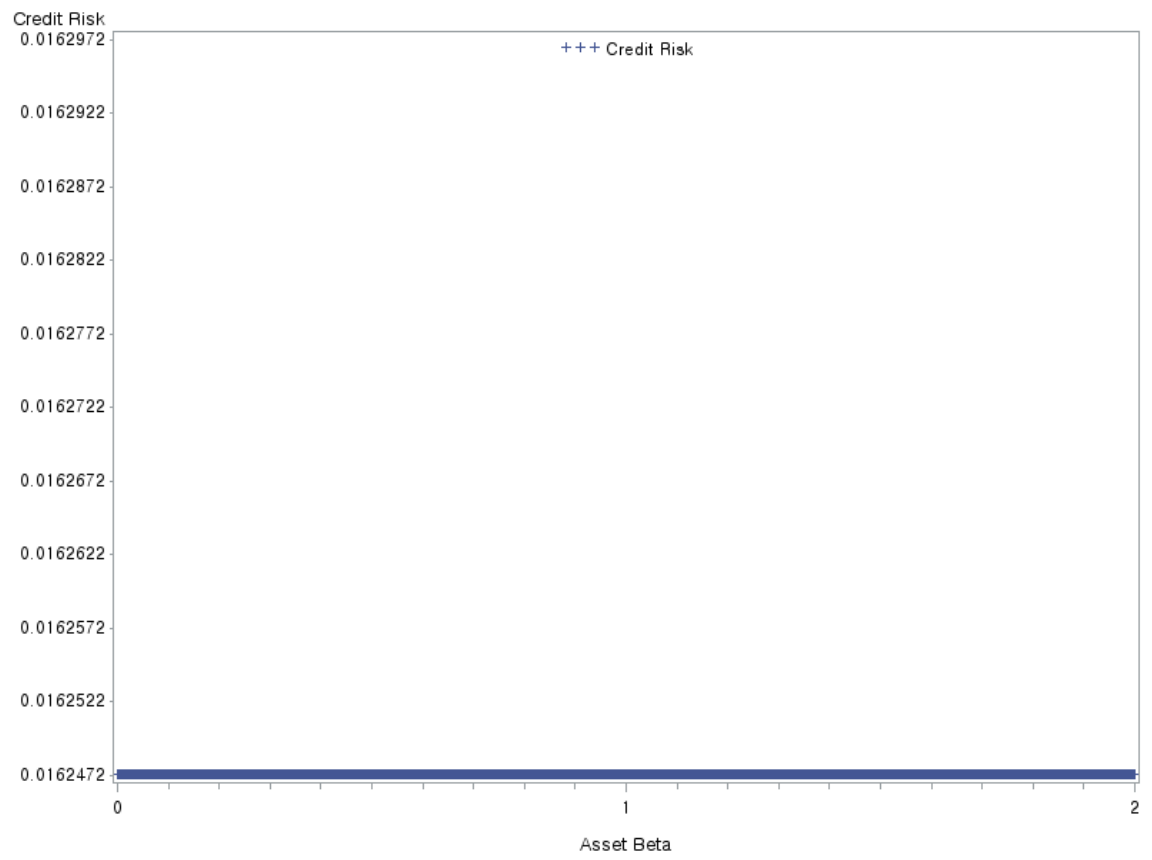

Figure 3. Credit risk and asset beta. Figure 3 reports the relations between the credit risk to the maturity as expected option return and the asset beta. The $\mathrm{X}$-axis and $\mathrm{Y}$-axis stand respectively for asset beta values and its corresponding credit risk values obtained from the simulation. Blue crosses are respectively for the relation between the credit risk and asset beta value.

inverse (direct) depending on the cases when the relation between credit risk and market risk premium is direct (inverse). These imply that the influence of the market variance measureable to the credit risk measurable is strongly different in the linkage between market risk premium and market variance.

Figure 3 reports the relation between credit risk and asset beta. In figure 3, X-and $\mathrm{Y}$-axis stand respectively for different asset beta values and its corresponding credit risk ones as calculated with the simulation inputs for the other simulation inputs being equal. As the figure shows, credit risk decays most exponentially so that the credit risk looking like flat as asset beta increases. 


\section{CONCLUSION}

This article develops the credit risk of a risky bond as expected option return observable. The credit risk is a function of several factors including the expected underlying asset variance observable. The underlying asset variance positively influences the credit risk; however, the asset beta negatively affects the credit risk. Moreover, market variance may affect the credit risk negatively in some conditions and positively in other ones. These imply that relations between the expected return of a risky bond and the underlying asset risks measurable are affected by what asset risks are defined with and how they are measured with data.

Such as Vega, parameters in continuous time models are difficult to measure with data time stamped. Among the parameters, the examination of the linkages with data has been a challenge for financial economists. The challenge is related to the fact that the empirical results are influenced by the time horizons that the linkages are observed over. In the investigation of the linkages with data, the consideration of the influence, measurement errors from the difference between time horizons, is often critical rather than what risks are defined with. One of the method to reduce the measurement errors is that the integral forms of continuous time models are applied. This article discusses the integral form of Merton (1974) and the relations between credit risk and asset risks as measurable.

\section{REFERENCES}

Bharath, S. T. and T. Shumway (2008), "Forecasting default with the Merton distance to default model," Review of Financial Studies, 21(3), 13391369.

Black, F. and M. Scholes (1973), "The pricing of options and corporate liabilities," Journal of Political Economy, 81(3), 637-654.

Broadie, M., M. Chernov, and M. Johannes (2009), "Understanding index option returns," Review of Financial Studies, 22(11), 4493-4529.

Chaudhury, M. (2017), "Volatility and expected option returns: A note," Economics Letters, 152, 1-4.

Coval, J. D., and T. Shumway (2001), "Expected option returns," Journal of Finance, 56(3), 983-1009.

Galai, D., and R. W. Masulis (1976), "The option pricing model and the risk 
factor of stock," Journal of Financial Economics, 3(1-2), 53-81.

Goyal, A., and A. Saretto (2009), "Cross-section of option returns and volatility," Journal of Financial Economics, 94(2), 310-326.

$\mathrm{Hu}, \mathrm{G}$. and K. Jacobs (2017), "Volatility and expected option returns," Available at SSRN.

Merton, R. C. (1973), "Theory of rational option pricing," Bell Journal of Economics and Management Science, 4(1), 141-183.

Merton, R. C. (1974), "On the pricing of corporate debt: The risk structure of interest rates," Journal of Finance, 29(2), 449-470.

Merton, R. C. (1980), "On estimating the expected return on the market: An exploratory investigation," Journal of Financial Economics, 8(4), 323361.

Owen, D. (1980), "A table of normal integrals," Communications in Statistics: Simulation and Computation, 9(4), 389- 419.

Rubinstein, M. (1984), "A simple formula for the expected rate of return of an option over a finite holding period," Journal of Finance, 39(5), 15031509.

Received March 27, 2018

Revised September 30, 2018

Accepted November 7, 2018 


\section{APPENDIX}

The appendix rephrases the formula of the expected holding to period return of a European call option (BSM 1973) (Rubinstein (1984)). The value of the European call option at a time $t$ for the period to the expiration $0 \leq t \leq T$ is, where $d=\frac{\ln \left(\frac{S_{t}}{K e^{-r(T-t)}}\right)+\frac{\sigma^{2}}{2}(T-t)}{\sigma \sqrt{T-t}}$,

$$
C_{t}=S_{t} N(d)-K e^{-r(T-t)} N(d-\sigma \sqrt{T-t})
$$

Then, the expected value of $C_{t}$ from current time 0 is the following,

$$
\mathbf{E}\left(C_{t} \mid S\right)=\mathbf{E}\left[\left(S_{t} N(d)-K e^{-r(T-t)} N(d-\sigma \sqrt{T-t}) \mid S\right)\right]
$$

The substitution of the underlying asset dynamics, $S_{t}=\operatorname{Sexp}$ $\left(\left(\mu-\frac{\sigma^{2}}{2}\right) t+\sigma \sqrt{t} z\right)$, into the equation (A2) yields the following,

$$
\begin{aligned}
\mathbf{E}\left(C_{t} \mid S_{t}\right)= & S e^{\mu t} \int_{-\infty}^{\infty} \exp \left(\left(\mu-\frac{1}{2} \sigma^{2}\right) t+\sigma \sqrt{t} z\right) N(d) \frac{1}{\sqrt{2 \pi}} \exp \left(-\frac{1}{2} z^{2}\right) d z \\
& -K e^{-r(T-t)} \int_{-\infty}^{\infty} N(d-\sigma \sqrt{T-t}) \frac{1}{\sqrt{2 \pi}} \exp \left(-\frac{1}{2} z^{2}\right) d z=I_{1}-I_{2}
\end{aligned}
$$

Now, the first integral $I_{1}$ is, where $A=\frac{\ln \left(\frac{S e^{\mu t}}{K e^{-r(T-t)}}\right)+\frac{\sigma^{2}}{2} T}{\sigma \sqrt{T-t}}$ and $=\sqrt{\frac{t}{T-t}}$,

$$
\begin{aligned}
I_{1} & =S e^{\mu t} \int_{-\infty}^{\infty} N(A+B(z-\sigma \sqrt{t})) \frac{1}{\sqrt{2 \pi}} \exp \left(-\frac{1}{2}(z-\sigma \sqrt{t})^{2}\right) d z \\
& =S e^{\mu t} \int_{-\infty}^{\infty} N(A+B z) \frac{1}{\sqrt{2 \pi}} \exp \left(-\frac{1}{2} z^{2}\right) d z
\end{aligned}
$$

The consideration of $\int_{-\infty}^{\infty}\left[N(A+B z) \frac{1}{\sqrt{2 \pi}} \exp \left(-\frac{1}{2} z^{2}\right)\right] d z=N\left(\frac{A}{\sqrt{1+B^{2}}}\right)$ (Owen 1980, p. 403) leads $I_{1}$ to the following,

$$
I_{1}=S e^{\mu t} N\left(\frac{A}{\sqrt{1+B^{2}}}\right)=S e^{\mu t} N(d)
$$


The second integral $I_{2}$ becomes the following, where $\mathrm{A}^{\prime}=$ $\frac{\ln \left(\frac{S e^{\mu t}}{K e^{-r(T-t)}}\right)-\frac{\sigma^{2}}{2} T}{\sigma \sqrt{T-t}}$,

$$
I_{2}=K e^{-r(T-t)} \int_{-\infty}^{\infty} N\left(A^{\prime}+B z\right) \frac{1}{\sqrt{2 \pi}} \exp \left(-\frac{1}{2} z^{2}\right) d z
$$

The consideration of Owen (1980, p. 403) also yields $I_{2}$ as the following,

$$
I_{2}=K e^{-r(T-t)} N(d-\sigma \sqrt{T})
$$

Therefore, the expected value of option over the end of the holding period less than the time to the expiration is

$$
\mathbf{E}\left(C_{t} \mid S\right)=I_{1}-I_{2}=S e^{\mu t} N(d)-K e^{-r(T-t)} N(d-\sigma \sqrt{T})
$$


